face on the piston impinges against a flat leather washer in the base of the needle. When these two come in contact there can be no residual fluid left in the syringe. The barrel

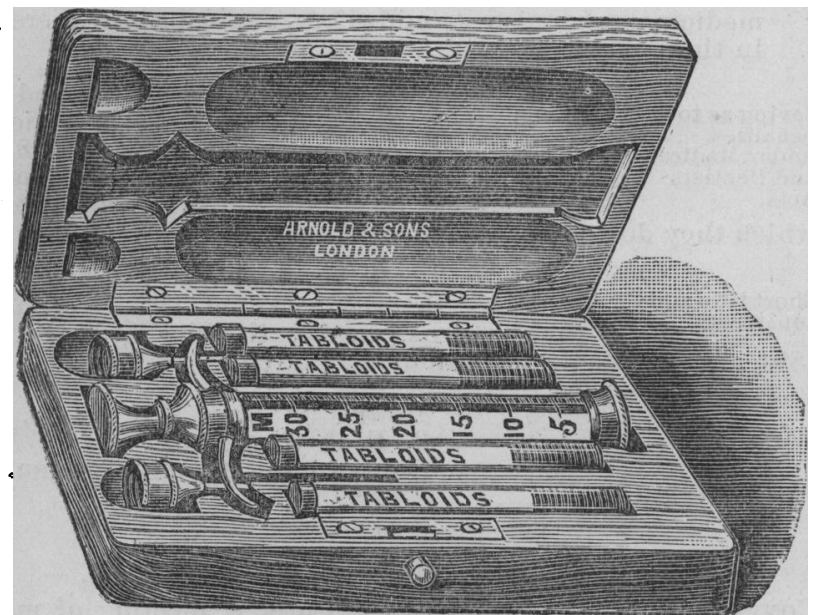

is fitted at its upper end with two horns, which enable it to be held steadily between the first and second finger, while depressing the piston with the thumb, thus leaving the other hand quite free for manipulating the skin. This is a very distinct improvement. The extreme toughness of the skin of his negro patients has induced Dr. Bowen to have the needles manufactured of a special tough yellow metal. The needle screws on over the barrel, so that a tabloid can be dropped into the cylinder and dissolved in it if desired. The barrel has a screw cap for carrying.

\section{BANDAGE SHOOT.}

Mrassas. Reynolds and Branson, 13, Briggate, Leeds, have made a very convenient bandage shoot to hang on the wall. Its construction will be understood from the accompanying

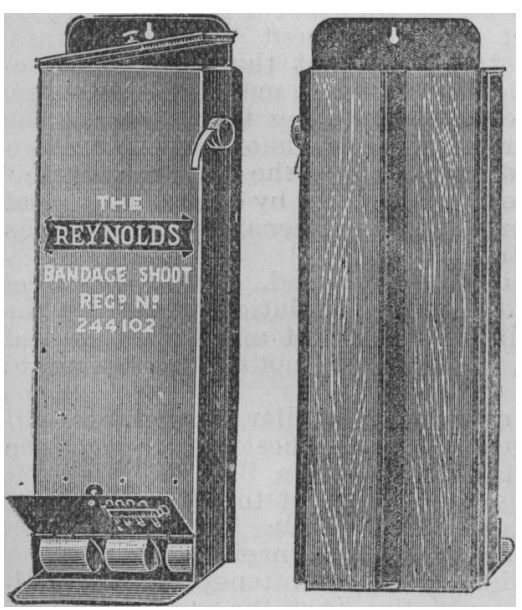
drawing. The specimen sent is designed to hold the three sizes of bandages in ordinary use, which can be withdrawn as wanted from the slot at the bottom. The shoots are filled from the top. At the side is a small receptacle for tape strapping. The invention will serve to keep bandages clean, and will be altogether found a very tidy addition to the surgery. At the back is space for two wooden splints, suitable for arm or leg. The larger size, for two dozen 4 inch, two dozen 3 inch, two dozen $2 \frac{1}{2}$ inch, two dozen 2 inch, and three dozen finger bandages, costs 17s. $6 \mathrm{~d}$. empty. The smaller size for one dozen 3 inch, one dozen 2 inch, and one dozen and a-half finger bandages, costs 10s. empty.

THE MOVILLETTE.

THE Movillette is a rigid pince-nez for astigmatic and other glasses, which ean be put on and off with one hand. The glasses are held in their place by two plaquets, which are kept applied to the sides of the nose by springs, the plaquets themselves being adjustable by a hinge to varying shaped noses. For putting on and off, the plaquets are separated by pressure with the thumb and forefinger on two spurs which

project slightly forwards on each side of the nose-piece. By this arrangement the glasses can be applied and removed by

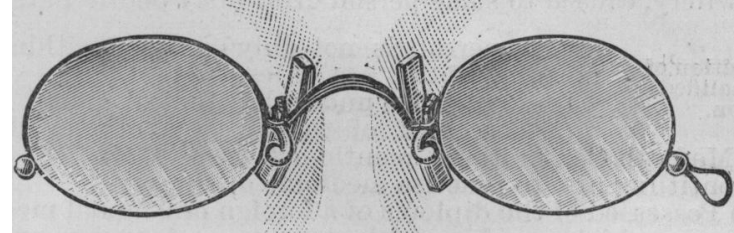

one hand only - a great advantage to public speakers and others who only need their glasses intermittently. They are made in four different sizes by Messrs. J. Raphael and Co., 13, Oxford Street, W.

\title{
THE AMENDMENT OF THE MEDICAL ACTS.
}

\section{Draft Bill of the Parliamentary Bills Commitee.}

At its last meeting the Parliamentary Bill Committee had before it clauses for a Bill for the amendment of the Medical Acts, which had been drafted according to its instructions by Mr. Muir Mackenzie, and Mr. R. W. Turner and Mr. B. F. C. Costelloe. The alternative clauses suggested by these gentlemen were in many instances nearly identical, and the differences were often merely verbal. It has appeared, therefore, that it would be convenient to have an agreement by the three barristers consulted as to the wording they would recommend. The Bill printed below is the considered form, signed by the three barristers, and it is printed here for the convenience of the Branches, who have been requested to consider the Bill at an early date, and to forward their observations to the Chairman of the Parliamentary Bills Committee. It is hoped that communications from the Branches upon the subject may be received by the end of February or early in March, in order that they may be considered and digested, and submitted to the Parliamentary Bills Committee.

$A$ Bill intituled an Act to Amend the Law relating to Unqualified Persons who practise Medicine and Surgery.

$\mathrm{Be}$ it enacted by the Queen's Most Excellent Majesty by and with the advice and consent of the Lords Spiritual and Temporal and Commons in this present Parliament assembled, and by the authority of the same, as follows:-

Punishment of unqualified persons who cal or surgical titles. Medical Specialist, Medical Dispenser, Apothecary, Aurist, Oculist, Ophthalmist, Accoucheur, Medico-Herbalist, Medico-Electrician, or any of these or the like titles with any added words, variations, or designations, or

(b) Any title, style, addition, or description directly or indirectly implying that he is the possessor of any degree in or licence to practise medicine, or surgery, or midwifery, or is in fact possessed of the skill necessary for the practice of medicine, or surgery, or midwifery, or any branch of medicine or surgery, or the performance of any operation in surgery or midwifery, or the administration of any medical treatment, shall for each offence be liable, on summary conviction under the Summary Jurisdiction Acts, to a penalty not exceeding twenty pounds, and to imprisonment in default of payment for not longer than one calendar month, and on conviction upon indictment to imprisonment for not longer than one year, with or without hard labour, and with or without the option of a fine, provided always that no person shall be liable to imprisonment without the option of a fine unless it shall be proved that he has by the performance of some opera- 
tion, or the administration of some treatment, or otherwise by or in the practice of Medicine, Surgery, or Midwifery, caused to some person grievously bodily harm.

Definition of unqualified

2. A person is not duly qualified within the person.

meaning of this Act unless he is

(a) Registered under the Medical Acts ;

(b) Possessed of the diploma of one of the Medical Corporations mentioned in the Medical Acts entitling him to practise medicine or surgery :

(c) Possessed of the diploma of a foreign or colonial medical body which would entitle him to registration in the Medical Régister as a foreign or colonial practitioner.

\section{Definition of taking and using titles by persons and institutions.}

3. For the purposes of this Act

(1) The words " title, name, style, addition or description" include any title, addition to a name, designation or description, whether expressed in words or by letters, or partly in one way and partly in another.

(2) A person shall be deemed to take and use a title, name, style or description who advertises, exhibits or holds out, or is party to the advertisement, exhibition, or holding out of any title, name or description of or concerning any institution. company, association, body, place, or premises whereby it is directly or indirectly expressed or implied that medicine or surgery or any branch of medicine and surgery is practised there, or who carries on. or is a party to the carrying on, by or at any such institution, or under or in connection with such institution, company, association, body, place, or premises the practice of medicine, surgery, or any branch of medicine or surgery.

\section{Legal pro-}

4. (1) All penalties under this Act shall be recovered summarily, and all proceedings against any person for an offence under this Act shall be taken under the Summary Jurisdiction Acts. * (2) Proceedings under this Act against any person for offences under this Act may be taken by the General Medical Council, or by a branch Council, or by a Medical Corporation, or by a private person.

(3) In the application of this Act to Scotland the expression "Summary Jurisdiction Acts", means the Summary Jurisdiction (Scotland) Acts.

\section{Evidence on}

5. In any prosecution under this Act prosecutions.

\section{(1) It shall}

that a persc name does not curre current year, which may be proved by production of a copy of a Medical Register for the time being purporting to be printed and published in pursuance of the Medical Acts, or by an affidavit of the registrar of the General Medical Council.

(2) In the case of a person entitled to be registered whose name does not appear in the current Medical Register, an affidavit by the registrar of the General Medical Council that the person is entitled to be registered, or that he is in fact registered, or an affidavit by the registrar, secretary, or other public officer of one of the Medical Corporations that the person is duly qualified under the diploma of the corporation, shall be sufficient evidence that the person is duly qualified unless the contrary is proved.

Saving as to persons who do not practise jn the United Kingdom.

. This Act shall not apply to

(1) Any person who has been duly registered under the Medical Acts, and whose name has been erased from the Medical Register on the ground only that he had ceased to practise.

(2) To a person possessed of any medical diploma granted in a British possession or foreign country legally entitling him according to the laws of that possession or country to practise there in medicine, surgery, or midwifery, who is temporarily or not ordinarily resident in, or who has for some bona fide operation or special purpose

"Note--" Medical Corporation" means under the Act of 1886 one fo the Corporations mentioned in the Act. "Person " includes public bodies by the Interpretation Act. of the like nature come to the United Kingdom, or who, if ordinarily resident in the United Kingdom, proves that he does not carry or intend to carry on the practice of medicine, or surgery, or midwifery, or any branch thereof, in the United Kingdom.

7. Nothing in this Act shall be construed to Saving as to penalties

under Medical and Dentists Acts. repeal or affect the operation of the provisions of the Medical Acts or the Dentists Act, 1878 , relating to penalties on persons for falsely pretending to be registered, or who take titles which they do not possess.

8. This Act may be cited as "The Medicab Short title and (Unqualified Practitioners) Act, 1895," and shall construction. be construed as one Act with the Medical Act. 1886, and the Medical Act therein referred to.

Resettled in consultation.

(Signed) Montague MUir Mackenzif.

B. F. C. Costrilloz.

December 21st, 1894. Richard WhrtbodRn TURner.

\section{THE REGISTRATION OF MIDWIVES.}

Convaned by the Midwives' Institute, a meeting of midwives and others interested in the promotion of a Bill for the registration of midwives was held on Wednesday afternoon at the Trained Nurses' Club, 12, Buckingham Street, Strand. Sir Frederick FitzW ygram presided, and briefly opened the proceedings by explaining the object for which the meeting was convened, although he avowed himself as opposed to the attempt to introduce a Bill.

Mrs. HaLl then read letters from several persons unable to be present, including Mr. H. F. Pease, M.P., Mr. Rathbone; M.P., Sir J. Williams, Dr. Danford Thomas, Dr. Playfair, and others, all of whom expressed themselves as being in sympathy with the object of the meeting.

The Chamman, after giving a short history of the move ment for the compulsory registration of midwives, said he was bound to say that in his opinion, if the Institute got a. charter which would give them a prescriptive right to issue certificates, that was as far as they had a right to go. It would require an Act of Parliament to impose any penalty, but he did not believe that there was any probability of Parliament passing any such measure. However, it was his duty to put before the meeting the clauses of the proposed Bill, which, among other provisions, would contain clauses for defining and safeguarding the term "midwife," rules for the examination of midwives by central and local: boards; the requisites for registration, penalties for acting as: midwives without registration, etc.

Some considerable discussion ensued, in the course of which Dr. Hraman said that the resolution passed by the. General Medical Council on the subject might be regarded as a general threat only, which he did not think they would. dare to enforce.

Dr. J. B. Potren also expressed a similar opinion.

Dr. Watr Buack suggested that the best course would be . to appoint a subcommittee to draw up a Bill, as he said it: was impossible for a meeting like that to discuss details: The Midwives Registration Association had drawn up a: scheme with great care, and it might be useful as a model on which to draft a Bill. The scheme was intended to be a selfsupporting one, with the exception that the county councils would be asked to keep a local register of the midwives in their own counties, and they would have to pay for them.

The CHaIrmaN inquired whether the meeting was of opinion that the best course was to proceed to obtain a Royah Charter first and afterwards an Act. That was certainly his. advice.

Miss Winson and others said that the Institute had not tha slightest idea of asking for a charter; they wanted nothing short of an Act dealing with the subject.

Dr. LeITH NAPInR proposed a resolution to the effect that: the meeting was of opinion that it was desirable to obtain. the passing of an Act; and this, after some discussion, was: agreed to.

The Chairman then vacated the chair, and his place wast 